
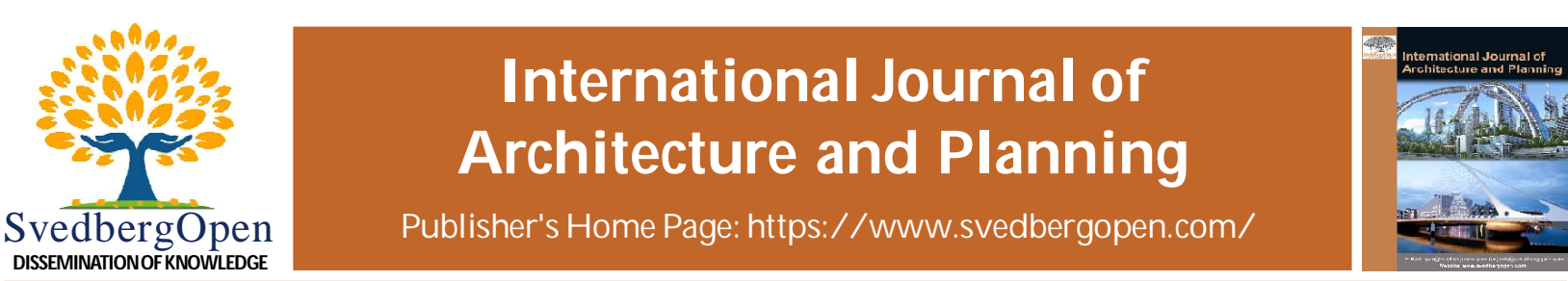

\title{
Are green infrastructure strategies suitable in arid climates? a design feasibility study from Jeddah city, Saudi Arabia
}

\author{
Abdulmueen Bogis ${ }^{1 *}$, Dean Bork ${ }^{2}$ and Patrick Miller ${ }^{3}$ \\ ${ }^{1}$ Ph.D. Scholar in Architecture and Design Research - Virginia Tech, MLA, BLA, Teacher Assistant, Landscape Architecture Department, \\ Abdulaziz University, Saudi Arabia. E-mail: bogis@vt.edu \\ ${ }^{2}$ Associate Professor, Landscape Architecture Program, Virginia Tech, United States. E-mail: drbork@vt.edu \\ ${ }^{3}$ Ph.D., FASLA, FCELA Professor of Landscape Architecture and Associate Dean for Graduate Studies and Outreach College of Architecture \\ and Urban Studies, Virginia Tech, United States. E-mail: pmiller@vt.edu
}

\section{Article Info}

Volume 1, Issue 1, March 2021

Received : 30 November 2020

Accepted : 16 January 2021

Published : 05 March 2021

doi: 10.51483/IJARP.1.1.2021.9-18

\begin{abstract}
This paper describes the feasibility and probable benefits associated with greening the Tahliah Channel, a concrete drainage channel that was originally built to relieve urban flooding in Jeddah city, Saudi Arabia. It includes an estimation of irrigation needs for channel greening based on a standardized planting specification. The study also demonstrates alternative strategies for meeting the required irrigation demand, including water harvesting and graywater reuse on a residential scale. The study shows that greening Tahliah Channel is possible relying mainly on graywater reuse from the surrounding buildings. Also, the study shows that rainwater harvesting is not a reliable source for irrigation. Rather, it can cover only part of the irrigation needs $(6 \%)$ and so can be used as a secondary supporting source. The positive results of this case study will be of interest to those in arid countries who are looking to upgrade and replace traditional, single function drainage infrastructure with more sustainable, green infrastructure systems. More specifically, the objectives of the study are consistent with the goals of the Saudi government's ongoing initiative that advocates for more resilient and sustainable cities (Vision 2030 year).
\end{abstract}

Keywords: Green infrastructure, Riparian restoration, Green corridor, Drainageway, Urban valley, Stormwater management, Flooding, Arid landscape, Sustainability, Urban ecosystem

(C) 2021 International Journal of Architecture and Planning. This is an open access article under the CC BY license (https://creativecommons.org/licenses/by/4.0/), which permits unrestricted use, distribution, and reproduction in any medium, provided you give appropriate credit to the original author(s) and the source, provide a link to the Creative Commons license, and indicate if changes were made.

\section{Introduction}

Within the first half of the $21^{\text {st }}$ century, the world's urban population is expected to increase by 2.5 billion. As a consequence, big cities will struggle to fulfill the economic hopes and dreams of those migrating from rural areas in hopes of a better quality of life. Many cities in developing nations are already struggling to provide minimum public services and infrastructure required for healthy living.

Research shows that, beyond basic needs, urban quality of life is improved when people have access to adequate public open spaces. For example, the World Health Organization (WHO) recommends that every city should have a minimum of 9 square meters of green space per person (Morar et al., 2014). There seems to be an obvious conflict between the demands for economic growth and expansion of adequate housing on the one hand, and the need for public and open spaces that promote a physically and socially healthy societies on the other. Providing adequate space for

\footnotetext{
* Corresponding author: Abdulmueen Bogis, Ph.D. Scholar in Architecture and Design Research, Virginia Tech, MLA, BLA, Teacher Assistant, Landscape Architecture Department, Abdulaziz University, Saudi Arabia. E-mail: bogis@vt.edu
} 
both public greenways and concrete stormwater drainageways to these new residents will only heighten the challenge. However, combining these uses into multiple use green infrastructure could help meet this challenge.

In temperate climate regions, green infrastructure (GI) is becoming an increasingly popular alternative to traditional gray infrastructure. Presumably, cities are adopting and implementing green infrastructure plans because they foresee multiple quality of life benefits for their citizens (EPA-US). One strategy for implementing such a plan is to replace conventional single function gray infrastructure with new forms of multifunctional pubic or green open spaces. Prominent projects of this type are occurring around the world. Some notable examples include Buffalo Bayou Promenade, Houston, Texas, Cheonggyecheon Stream, Seoul, South Korea, and Bishan-Ang Mo Kio Park, Singapore. However, is this possible in more arid regions of the world?

This paper answers this question by examining the potential of green infrastructure strategies on a concrete drainage channel located in an arid part of the world, Jeddah City, Saudi Arabia. The study demonstrates the possibility of greening concrete drainage channels, by examining a channel in Jeddah City, Saudi Arabia that was designed and constructed with a fairly narrow set of purposes. The objective is to design and evaluate a plan to increase public open spaces within an urban arid environment. The lessons learned from this case study will enhance our understanding of the application of green infrastructure principles to arid urban environments. The article begins by examining the context of Jeddah City in terms of its water resources. The article then examines a feasible scenario to convert the existing channel to a green channel. This done by examining four critical elements of a green channel in an arid climate. These are the plants (types and numbers) needed for a green the channel; the irrigation needs (volume of water and type of efficient irrigation system); the possible sources of water and the reliability of the source of water. The article ends with a discussion of the feasibility of green channels in arid climates.

\section{Context of Jeddah city}

Jeddah city is a rapidly growing urban region located along the arid west coast of Saudi Arabia (Figure 1). Jeddah lies on a coastal plain between the Hijaz mountain range and the Red Sea. The city is subject to serious seasonal flooding as water rushes from the mountains through the city on its way to the sea. More than 15 valleys, with watersheds of various sizes, pose flooding threats to Jeddah. In 2009 and 2010, Jeddah witnessed the greatest urban floods in the history of the city. These floods killed hundreds of people and destroyed properties (Bogis, 2015).

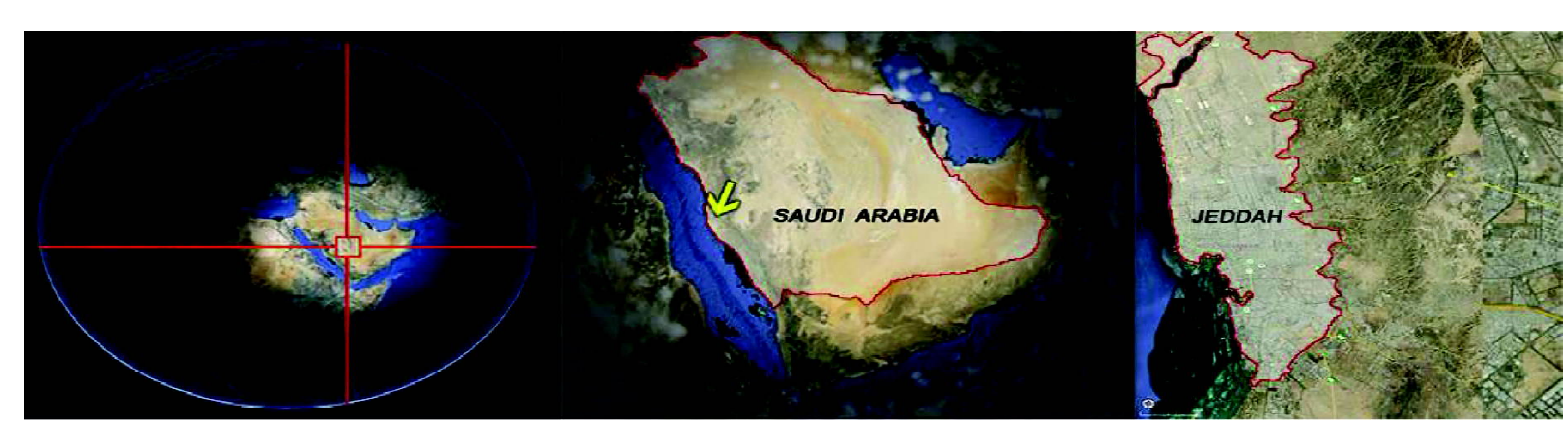

Figure 1: Location of Jeddah city

Source: reproduced by Abdulmueen Bogis from google earth maps

A network of concrete drainage channels covering almost 82 million acres (81,937,673 acres) and 14 dams were constructed in an effort to alleviate the threat of these regional flooding events. While this network is effective in conveying stormwater through the city, the channels do not eliminate all urban flooding or the associated property damage and loss of life (Figure 2). Residual flooding still occurs because the city's stormwater infrastructure was never adequately adapted to allow for the positive drainage of the runoff that is generated by the city itself.

Jeddah currently provides an average of $2 \mathrm{~m}^{2}$ per capita of public space in comparison to the $9 \mathrm{~m}^{2}$ recommended by the WHO_yet, the majority of the city's districts have less than $1 \mathrm{~m}^{2}$ per capita (Jeddah Municipality 2014a) (Figure 3). Currently, the channels in Jeddah do not support many outdoor activities. According to Jan Gehl, in Life Between Buildings (Gehl, 2011), communal activities in these places should include "children at play, greetings and conversations, communal activities of various kinds, and finally—as the most widespread social activity—passive contacts, that is, simply seeing and hearing other people" (Gehl, 2011). Conversely, the concrete channels in Jeddah have a tendency to become sites for unwelcome social behaviors (Figure 4). A working definition of anti-social behavior is provided by law enforcement officials in the UK. Behaviors that result in harm to individuals, the community, or the environment are 


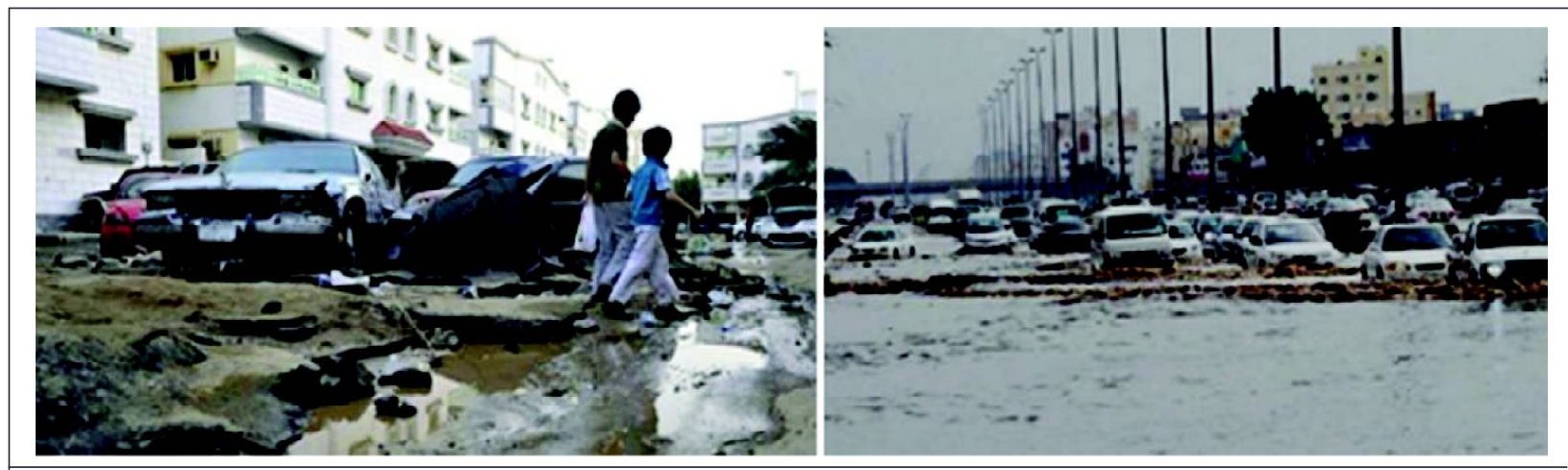

Figure 2: The engineered stormwater infrastructure fails to cope and adapt to excessive rain rates.

Source: Almadina News Paper

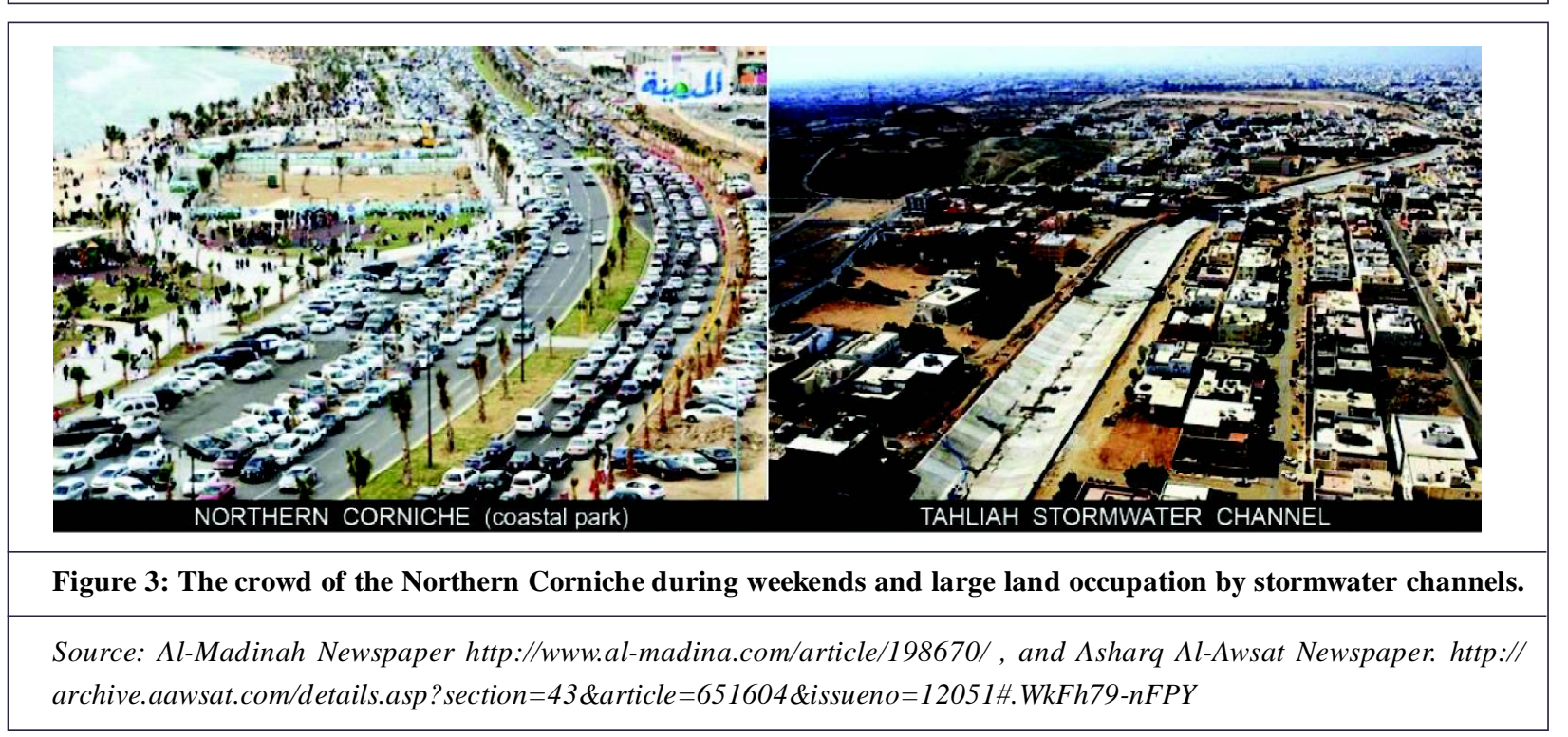

included (Police-UK). An example of anti-social behavior associated with the drainage channels in Jeddah is illegal dumping of raw sewage, among other crimes. As a solution, this study develops a strategy to improve the quality of the physical environment and provide good contact with urban green spaces. For instance, by turning these channels into linear parks, not only can Jeddah protect the environment by preventing the dumping of harmful waste into these channels, but also protect marine life and public health as a result.

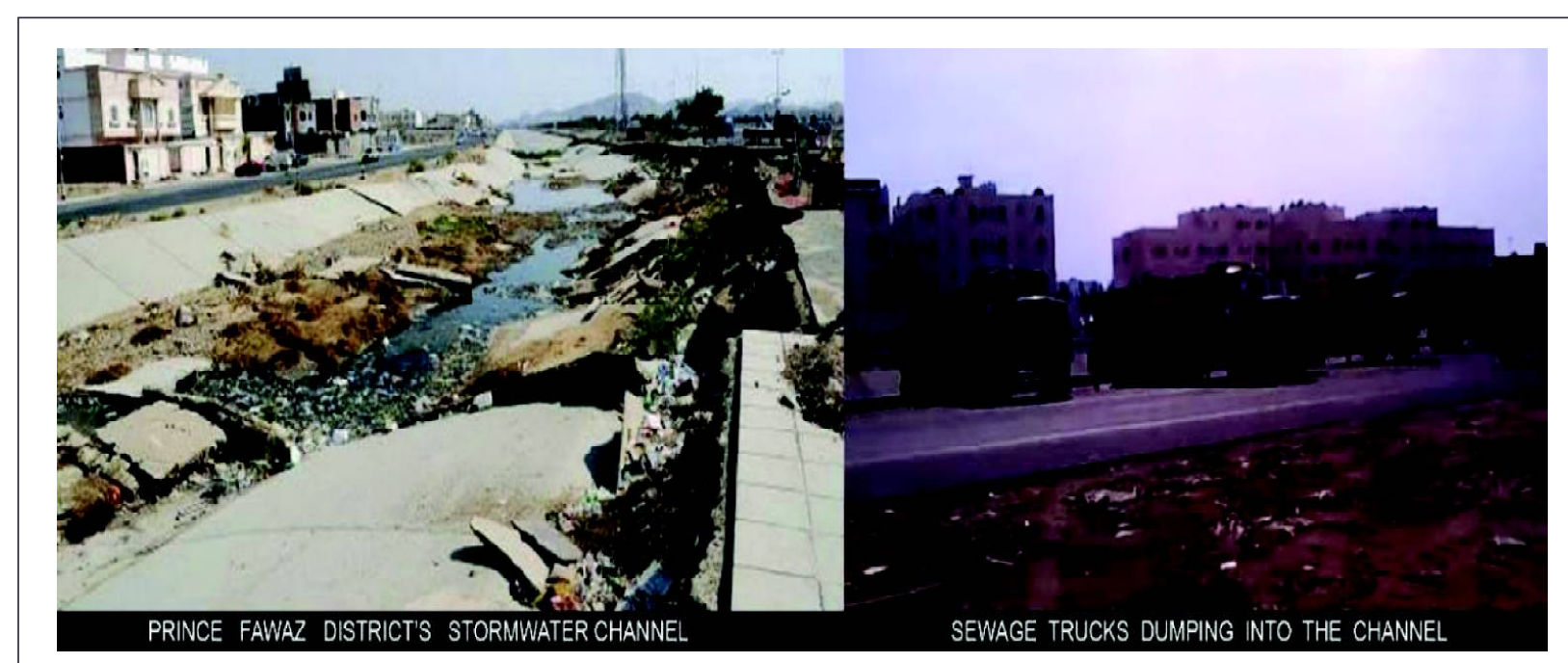

Figure 4: Dumping black-water and solid waste at the drainage channel of Prince Fawaz district, Jeddah city. 
Greening these channels may also help improve water management in Jeddah for one of many reasons. First, encouraging more rainwater harvesting from rooftops ${ }^{1}$ using Low Impact Development (LID) and green infrastructure practices, ${ }^{2}$ which can be implemented in the channels and the surrounding neighborhoods. This will help reduce the impact of urban flooding and the amount of discharged water in the sea-thereby protecting marine life. Moreover, reducing surface runoff will reduce subsequent infrastructure damage and impact. ${ }^{3}$ Second, turning these channels into green channels will encourage local wastewater recycling. This can be done by separating blackwater from graywater from the surrounding buildings in order to reuse it for irrigation of the green channels.

Currently, desalination is the only reliable source of water for Jeddah and many other cities in the Kingdom. Desalination provides Jeddah with the daily water needs of 972,400,000 L/day (256,880,904 gallons) for 3.4 million residents. The cost to the government in Saudi Arabian Riyals (SAR) for the desalination processes is $7 \mathrm{SAR} / \mathrm{m} 3$ (US $\$ 0.007 /$ gal) at a total daily cost of $6,806,800 \mathrm{SAR}$. This is heavily subsidized. Only $142,800 \mathrm{SAR}$ ( $2 \%$ of the total cost) is paid by the users for the entire daily desalination cost, at a rate of $0.15 \mathrm{SAR} / \mathrm{m} 3$ (US $\$ 0.04 / \mathrm{m}^{3}$ ) (Al-Ekhbariah TV Channel, 2012). Moreover, approximately $45 \%$ of the population is served by the main sanitary sewer system, but only $70,000 \mathrm{~m}^{3} / \mathrm{day}(18,492,044$ $\mathrm{gal} /$ day) of the treated wastewater of Jeddah is recycled for irrigation (Jeddah Municipality, 2014b).

Therefore, in the following sections, this article explores the feasibility of greening these channels by relying on graywater ${ }^{4}$ from the surrounding buildings to irrigate the plants in the channels. Moreover, this study also considers the feasibility of collecting rainwater from the surrounding buildings and within the channels to support any deficiency in the irrigation needs - and also to support part of the potable uses per household.

\section{Materials and method: The feasibility of greening the channel}

In order to test the feasibility, the Northern Channel (known as the Tahliah Channel) was selected among the other channels (Eastern, Airport, Northern and Southern Channels) because it is surrounded by highly populated districts, has a low amount of open spaces per capita $\left(2 \mathrm{~m}^{2} /\right.$ person), is located near a number of graywater sources (e.g., districts, schools, mosques, houses, etc.), and is close to one of the most active shopping mall streets (Tahliah Street). The future vision of the Municipality of Jeddah is to turn this channel into a green open space as reported in the Open Space and Leisure report (Jeddah Municipality, 2014a) by the Municipality; however, a plan for this has not yet been prepared.

\subsection{The water resources in Jeddah city}

After the 2009 and 2010 flood events, the US-based Architecture and Engineering Company (AECOM)_in cooperation with Jeddah Stormwater Drainage Program Department—was tasked with resolving this urgent problem. As a result, the total number of constructed dams in Jeddah is now 14 and includes four main and other sub-concrete channels. According to Zack Isnasious Jeddah Stormwater Drainage Program and AECOM, "The dams were designed to control a 100-year storm with a storm length of 8 to 15 days. The dams were not designed to harvest water, because of the unreliable precipitation patterns and potential evaporation rates" (Tables 1 and 2).

Historically, however, the old city of Jeddah (now referred to as the Al-Balad District) actively harvested rainwater for its population. Originally, many of the ancient buildings in the old city were provided with underground cisterns to store rainwater harvested from the top of the roofs during Ottoman rule (between the $15^{\text {th }}$ and $19^{\text {th }}$ centuries) (Burckhardt, 1829) (Figure 5).

Figure 6 illustrates a possible model of rainwater harvesting per rooftops stored in separate tank from the graywater and blackwater. This to make it easier to use each type of water for the purpose for which it is stored (i.e., rainwater for potable uses or additional source of irrigation, graywater for irrigation, blackwater to send it to treatment plants).

\subsection{First: What are the suggested plants to green Tahliah Channel?}

This section answers the question how much water will be needed to irrigate the plants suggested for the green channel. A model was developed to calculate the daily irrigation needs year-round, including a prototypical specification of plants with known irrigation needs. The suggested types of planting specification are generated from the "Water

This will help reduce the water volume discharged into the drainage channels and reduce urban flooding. Reusing rainwater helps cut the percentage of daily water needs in Jeddah, which means cost reduction in desalination.

For example, detention ponds, cisterns, raingarden, bioretention, etc.

Examples include: damaging road and walkways, mixing sewage water with rainwater, and slowing the flow of traffic in the city thus, affecting the economy.

4 Separating blackwater and graywater from the surrounding buildings can create an opportunity to bio-treat the graywater locally and reuse it to cover irrigation needs for the proposed landscape at these channels. As a result, the total cost of sewage treatment plants will be reduced. 
requirements for most of the aesthetic plants" manual that is used by the municipality of Jeddah. As previously mentioned, it includes 4 local palms, 4 trees, and 20 shrubs (Table 2). In order to cover both sides of the selected channel (the Tahliah Channel) and achieve at least 50\% greenery, 666 of the planting specifications of plants would be required to implement a green design for the channel's total area of $346,429 \mathrm{~m}^{2}$ (85.60447 acres). This number (666 planting specification) was calculated by dividing the channels into 18 segments, each segment including 37 planting specifications, and each planting specification will be irrigated by each house or building in front of it. The size of each planting specification is estimated based on the required distance between the palms and trees to green $50 \%$ of Tahliah Channel (Figure 7). Table 2 illustrates the required daily irrigation needs for each plant type used in the planting specification, varied in volume depending on the time of year (i.e., month). The total annual irrigation needs for each

Table 1: Average precipitation in Jeddah from 1981 to 2011 and Evapotranspiration (ETo) data (Source: Ministry of Defense and Aviation-National Meteorology and Environment Center of Saudi Arabia, and Ricks, 1992)

\begin{tabular}{|l|c|c|c|c|c|c|}
\hline \multirow{2}{*}{ Month } & \multicolumn{2}{|c|}{ Precipitation (inch) } & \multicolumn{2}{c|}{ Evapotranspiration } & \multicolumn{2}{c|}{ Total (inch) } \\
\cline { 2 - 7 } & Average & Extreme & Year & Inch & Average & Extreme \\
\hline Jan & 0.42 & 2.98 & 2011 & 0.32 & 0.1 & 2.66 \\
\hline Feb & 0.12 & 1.77 & 1995 & 0.4 & 0 & 1.37 \\
\hline Apr & 0.09 & 1.0 & 1998 & 0.42 & 0 & 0.58 \\
\hline May & 0.09 & 1.7 & 2005 & 0.47 & 0 & 1.23 \\
\hline Jun & 0.007 & 0.17 & 1987 & 0.49 & 0 & 0 \\
\hline Jul & 0.007 & 0 & $1981-2011$ & 0.49 & 0 & 0 \\
\hline Aug & 0.01 & 0.39 & 1998 & 0.51 & 0 & 0 \\
\hline Sep & 0.003 & 0.08 & 2010 & 0.49 & 0 & 0 \\
\hline Oct & 0.03 & 1.0 & 1997 & 0.42 & 0.5 & 0.58 \\
\hline Nov & 0.87 & 11.2 & 1996 & 0.38 & 0.12 & 10.82 \\
\hline Dec & 0.43 & 2.58 & 2010 & 0.31 & 19.51 \\
\hline Total Average Annual Precipitations & & & & 0 & 0 \\
\hline
\end{tabular}

Table 2: The individual water requirements for plant materials contained in the planting specification. The Annual Irrigation (g) counted the additional $10 \%$ water lost in the dripping system (Source: modified by Abdulmueen Bogis from Jeddah's Municipality Irrigation Guide)

\begin{tabular}{|l|l|l|l|l|l|l|l|l|l|l|l|l|l|l|l|}
\hline Month & Jan & Feb & Mar & Apr & May & Jun & Jul & Aug & Sep & Oct & Nov & Dec & $\begin{array}{c}\text { Annual } \\
\text { (g)/ } \\
\text { plant }\end{array}$ & $\begin{array}{c}\text { No. } \\
\text { of } \\
\text { plants }\end{array}$ & $\begin{array}{c}\text { Annual } \\
\text { Irrigation } \\
\text { (g) }\end{array}$ \\
\hline $\begin{array}{l}\text { Palms } \\
\text { g/day }\end{array}$ & 13.2 & 13.2 & 17 & 17 & 17 & 26.4 & 26.4 & 26.4 & 17 & 17 & 17 & 13.2 & $\mathbf{6 7 2 7 . 8}$ & $X^{4}$ & $\mathbf{2 9 8 7 1}$ \\
\hline $\begin{array}{l}\text { Big Trees } \\
\text { g/day } \\
\text { cover } \\
>\text { 65ft2) }\end{array}$ & 10.5 & 10.5 & 13.2 & 13.2 & 13.2 & 21 & 21 & 21 & 13.2 & 13.2 & 13.2 & 10.5 & $\mathbf{5 2 9 2 . 6}$ & $X^{4}$ & $\mathbf{2 3 4 9 9}$ \\
\hline $\begin{array}{l}\text { Small } \\
\text { Shrubs } \\
\text { g/day }\end{array}$ & 2 & 2 & 2.64 & 2.64 & 2.64 & 3.96 & 3.96 & 3.96 & 2.64 & 2.64 & 2.64 & 2 & $\mathbf{1 0 2 7 / 4 4}$ & $X^{20}$ & $\mathbf{2 2 8 0 9}$ \\
\hline $\begin{array}{l}\text { Total } \\
\text { Gallons }\end{array}$ & $\mathbf{8 8 4}$ & $\mathbf{8 8 4}$ & $\mathbf{1 1 3 0}$ & $\mathbf{1 1 3 0}$ & $\mathbf{1 1 3 0}$ & $\mathbf{1 7 6 7}$ & $\mathbf{1 7 6 7}$ & $\mathbf{1 7 6 7}$ & $\mathbf{1 1 3 0}$ & $\mathbf{1 1 3 0}$ & $\mathbf{1 1 3 0}$ & $\mathbf{8 8 4}$ & $\mathbf{1 3 , 0 4 8}$ & & $\mathbf{7 6 , 1 8 0}$ \\
\hline
\end{tabular}




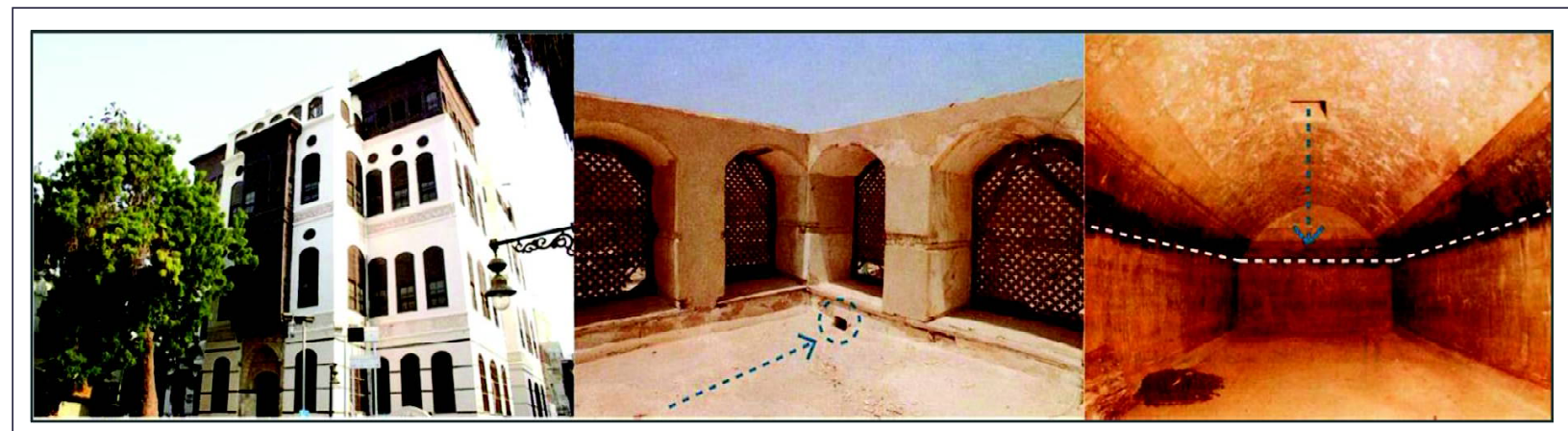

Figure 5: Traditional rooftop rainwater harvesting with underground cistern (Image of Nasif House

Source: The National Center for Research and Documentation at Jeddah City

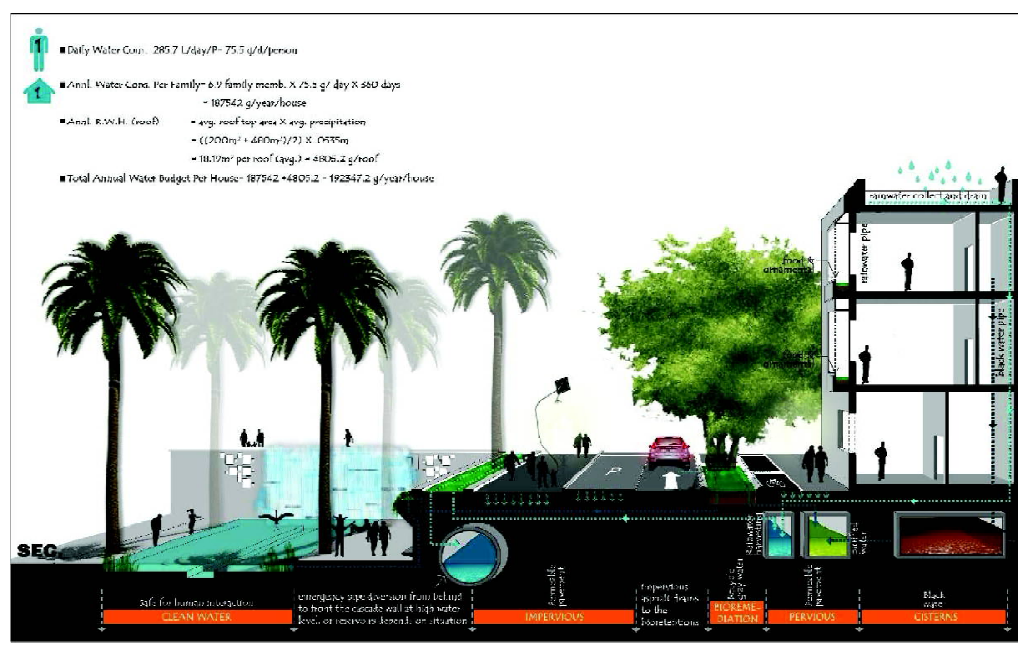

Figure 6: A model of rainwater harvesting (RWH) collecting from roofs and other surfaces, bio-treatment planters for gray water, and daily deposit of clean water in the suggested stream per house

Source: Bogis, 2015

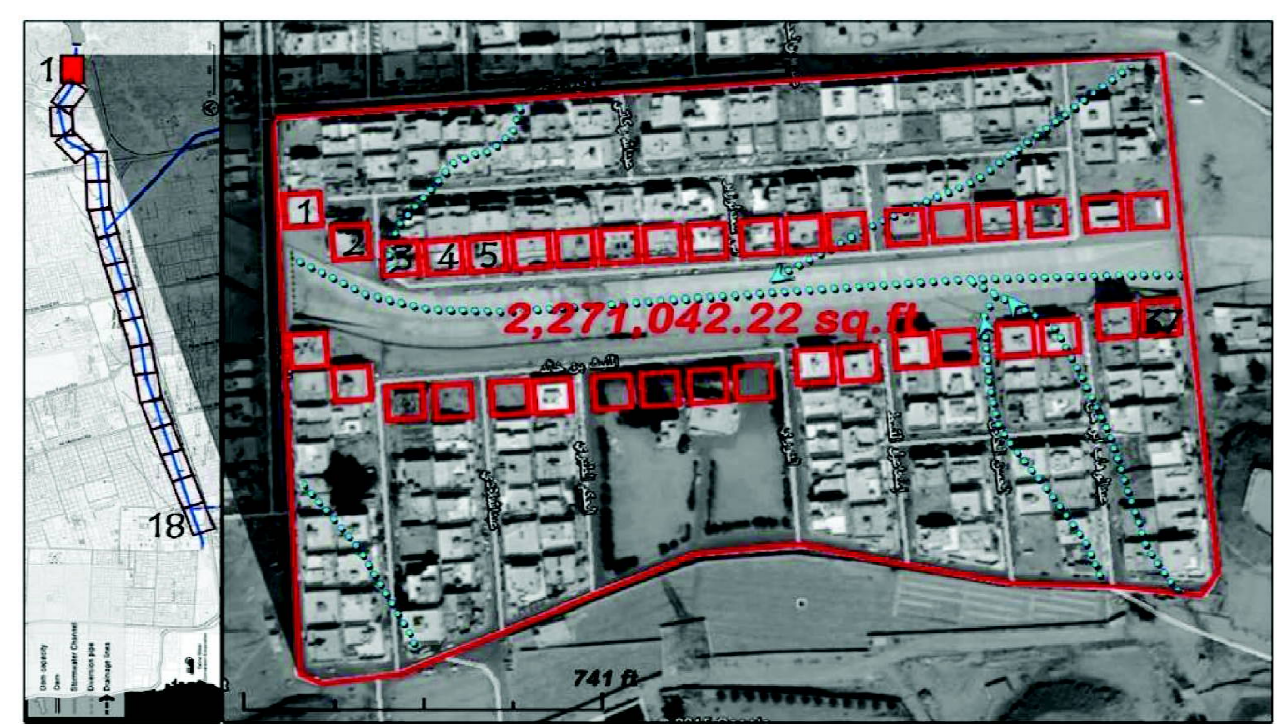

Figure 7. From left to right, the number of possible segments (18) multiplied by (37) units to green $50 \%$ of Tahliah 333 Channel 
planting specification is 76,180 gallons and the total annual irrigation needs for the 666 planting specification is 50,735,880 gallons. The next section demonstrates the available water sources (rainwater harvesting or graywater) to irrigate the 666 planting specifications. It reinforces the authors' claims that these are reliable sources of water to irrigate each planting specification.

\subsection{Second: What are the economically feasible water sources near the Tahliah Channel?}

This section presents the water sources available to irrigate the 666 planting specifications, and also illustrates the cost of desalination, and the cost savings when harvesting rainwater and recycling graywater are implemented. The calculation of the economic feasibility here is based on the reduction in the overall cost of water provision from the desalination (for potable use) and the blackwater treatment (for irrigation) by rainwater harvesting and graywater reuse per house.

In this case, there are three feasible sources of water for irrigation: desalination, graywater, and rainwater. First, desalinating sea water is currently considered the main source of water for the city. More than 250 million gallons per day are desalinated to cope with the daily need of 3.4 million residents at a cost of $\$ 1,815,146$ per day. Moreover, the stations that supply the current daily need of water are run by petroleum oil. This makes this source very expensive and undesirable for nonpotable water uses (irrigation). The second possible source is graywater. Following the high cost of desalination and high rate of water consumption per person ( $75 \mathrm{gal} /$ person/day), an excessive daily waste of a valuable source of the municipal water that is dumped into the sea without pretreatment or reuse because of the low capacity of the existing wastewater plant. An approximate $45 \%$ of the population is served by the main sanitary sewerage, but only $18,492,044 \mathrm{gal} /$ day of the treated wastewater of Jeddah is recycled for irrigation (Jeddah Municipality, 2014b). With an average of 6.4 members in each Saudi household and a consumption of 75.5 gallons per person per day, 173,952 gallons of gray water can be generated per year, per household. This surpasses the irrigation needs (76,180 gal/year) of an individual planting specification by more than two-fold (112\%). ${ }^{5}$ While the total irrigation needs to irrigate the 666 planting specifications is 50,735,880 gallons, the Tahliah Channel is surrounded by eight districts (Alandalus, Alaziziyah, Alfaisaliyah, Assafa, Assamer, Arrawdah, Arrihab, and Alwaha), with a total approximate population of more than 527,010 who can generate about 14,324,131,800 gallons of wastewater per year-which is 282 times more than the need to irrigate the 666 planting specifications. This confirms that these 8 districts alone can provide enough grey water to irrigate a channel the size of Tahliah Channel. While this is going to save money from desalinization it will cost money to install storage tanks and infrastructure for grey water. While there will be some significant up-front costs there should be long term savings. A final source is rainwater harvesting per house. The total average mean of rainfall per year is $45 \mathrm{~mm}$ (1.77 in) (calculated from the Table 1). The potential for harvesting rainwater in Jeddah is discussed in more detail in the section below.

\subsection{Third: What is a feasible rainwater harvesting system for households and the watershed within the boundary of the selected channel?}

In this section we test whether this source is reliable for irrigation or can be used as a back up source. As a rainwater harvesting source, we used the following equation from the book Harvesting Rainwater for Landscape Use by Waterfall (2004): The potential rainwater harvesting volume (Supply) using the following equation:

\section{(1) Harvested Water $(H W)($ in Gallons $)=P($ inches $) \times$ Area $(f t 2) \times C \times 0.623$}

Where $P$ is the average annual rainfall that falls in Jeddah city. The parameter $C$ is a runoff coefficient based on the Rational Method. The conversion factor 0.623 is used to measure the supply in US gallons.

The average household or villa area size around Tahliah Channel is $4305.56 \mathrm{ft} 2\left(400 \mathrm{~m}^{2}\right)$ (Al-Hathloul and Anis-urRahmaan, 1985; Guizani, 2016) (Al-Hathloul and Rahman, 2011; Cited by Guizani, 2016). Therefore, the average potential of rainwater harvesting is 4,747.7 gallons per roof per year. This amount can covers about $6 \%$ of the irrigation requirements of an individual planting specification. The possible volume of rainwater harvesting can at least cover $9.7 \%(84,556.8$ gal/year) of all household members' (6.4/house) needs (for flushing, bathing, laundry, food \& drink, cooking faucets) ${ }^{6}$ (Ashrq Al-Awsat) every year if we did not use it for irrigation (see calculations below).

Rainwater alone will not satisfy requirements in the dry months and therefore harvesting graywater (173,952 gal./ year/household) is only reliable source year around as long as the production of potable water meets the needs of the city. Therefore, for more efficient reliable irrigation sources and lower possible cost to install storage tanks and infrastructure, this study suggests: (1) the size of tank for the harvested rainwater should cope with the average yearly

This means even with half of this assumed volume the system should have no irrigation need issue.

The daily water usage of a Saudi person per household breaks down to: 25 gal for flushing, 20 gal for bathing), 10 gal for laundry, 2.9gal for food \& drink, 2.9 gal for cooking, and 2.9 gal for faucets (Ashrq Al-Awsat Newspaper, 2005). 
potential harvesting to use it as an alternative source for irrigation or potable uses; (2) the graywater tank must cope with the yearly possible graywater production per household.

\section{Given Information:}

- Average Saudi family members is 6.4 people/house

- Average daily wastewater production per person is 75.5 gallons/person/day (483.2 gal/day/house)

- Daily water usage is $63.7 \mathrm{gal}$ (for flushing, bathing, laundry, food and drink, cooking faucets)

- Average annual precipitation is $45 \mathrm{~mm} /$ year

- Average rooftop area in the selected area is $4305.56 \mathrm{ft} 2$

- Rooftop coefficient (C) is 1

- Annual Evapotranspiration (ETo) is 5.2 in

- Dripping irrigation efficiency is $90 \%$

- Plant water requirements in Table 2 (see Methodology section)

- Residential concrete cistern cost is $\$ 0.13 /$ gal

- Tertiary treatment cost is $\$ 0.005 /$ gallon, and desalination cost is $\$ 0.007 /$ gal

- $40 \%$ of the channel area is a running stream with a depth of $50 \mathrm{~cm}(1.6 \mathrm{ft})$, with an average cross-section area of $3.5 \mathrm{~m}^{2}$ $(37.6 \mathrm{ft} 2)$

\section{Calculations:}

(1) Annual Wastewater Production Per House = 6.4 x 75.5 (g/person/day) x 360 (days)

$$
=173,952 \mathrm{gal} / \mathrm{year} / \text { house }
$$

(2) Harvested Water $(\mathrm{HW})($ in gallons $)=\mathrm{P}($ inches $) \times$ Area $(\mathrm{ft} 2) \times \mathrm{C} \times 0.623$

$$
\begin{aligned}
= & 1.77(\text { in }) \times 4305.56(\mathrm{ft} 2) \times 1 \times 0.623 \\
= & 4,747.7 \mathrm{gal} / \text { year/roof (equal to } 44 \% \text { of water needs per } \\
& \text { person per year for drinking, food, and cooking only) }
\end{aligned}
$$

(3) Annual Potential Generated Water Per House = Annual Wastewater + HW

$$
=(173,952+4,747.7)=178,699.7 \mathrm{gal} / \text { year/house }
$$

(4) Annual Irrigation Needs Per Planting Specification Considering the Dripping System Efficiency $(90 \%)=10 \%($ water loss to dripping irrigation system $)+$ individual planting specification needs $=$ $7,618 \mathrm{~g} / \mathrm{y}+76,180 \mathrm{~g} / \mathrm{y}=83,798 \mathrm{gal} /$ year. That means only graywater per household can support the annual irrigation needs (of 50\% greenery) with 90,154 gal/year extra.

\section{Results}

Based on the study, it is feasible to green channels in arid climates relying mainly on reusing locally bio-treated graywater. Moreover, the study shows that not only is it possible to irrigate the 50\% greenery of Tahliah Channel, we can actually irrigate a much larger area, but we need to enlarge the tanks capacity. This is only by developing the three separate tanks systems for graywater, blackwater, and rainwater per house unit only from the houses surrounding Tahliah Channel. The question is then, what if this system were to be implemented all over the city?

This study shows strong possibility to increase the open space system within Jeddah. This is critical, because of land shortage for public spaces and the challenges of water resources. The recycling process of the suggested model can help reduce the cost of wastewater treatment and the expected rise in the water table due to leakage from existing septic tanks and sanitary pipes, and also the cost of maintaining them. Moreover, an even better solution to this problem is reusing the graywater to green the channels, and not installing more sewer pipe networks, in order to reduce the possibility of a raising water table in Jeddah-whose impact could affect the durability of buildings (Cooke and Ronald, 1982; Cited by Vincent, 2003). This study demonstrates that it is possible to harvest rainwater in each house, which could help reduce the cost of desalination water and the dependency on fossil fuels (Darwish et al., 2009), which may help reduce the impact of Urban Heat Island (UHI) associated with burning fossil fuels for energy. 
The study proposes only $50 \%$ greenery of Tahliah Channel be covered by vegetation with the 666 of the individual planting specification with a very limited number of plant types. However, if the municipality wanted to increase this percentage and increase the ecological performance of these channels it would be possible as long as it remains within the annual water budget available from the discussed water sources (e.g., RWH and gray water). It is expected that, by implementing more green infrastructure practices surround Tahliah Channel, the amount of non-source pollution can be controlled and treated from the areas that drain to Tahliah Channel as calculated by Bogis (2015) (Figure 8).

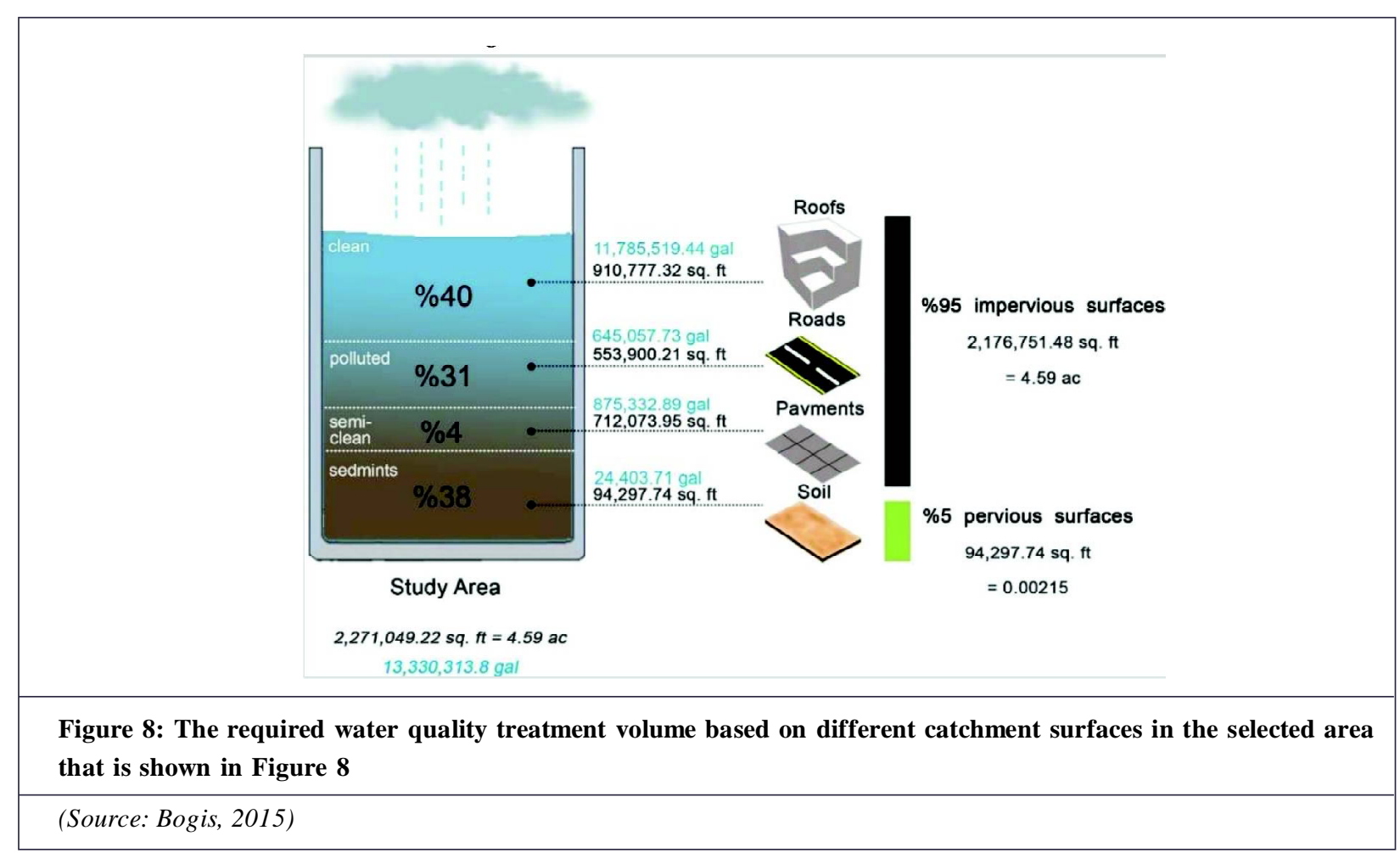

\section{Discussion and conclusion}

The study answer one of the challenges that may hinder the retrofitting of concrete channels into green channels in one of the most water scarce countries in the world. The study then suggests one of the methodologies to answer whether green infrastructure can be possibly implemented in arid countries or not. That was by testing the relationship between the independent variables (aridity, water resources, and plants irrigation needs) and the dependent variable (increase green spaces).

This study will be of interest to those in arid countries who are looking to upgrade and replace traditional, single function drainage infrastructure with more sustainable, green infrastructure systems. More specifically, the recommendations of the study are consistent with the goals the Saudi government's ongoing initiative that advocates for more resilient and sustainable cities (Vision 2030 year). These recommendations include: (1) implementing cisterns to harvest rainwater per house to reduce the cost of desalination of seawater; (2) implementing separate gray and blackwater systems per house to reduce the required infrastructure and facility and the maintenance for treating wastewater; (3) retrofitting the current concrete channels into green channels to increase the percentage of public open spaces per capita (one of Jeddah City's plans), attract investment, increase walkability, increase biodiversity, and improve the quality of life of the adjacent neighborhoods of the four channels by reducing the reliance on cars, the gas emission effect, and the urban heat island effect, and obesity rates, among others; (4) fostering a healthy relationship with academic and scientific researchers. Universities in return will be encouraged to support scholars and students to establish environmental, social, and economic research that are related to the future redevelopment of these channels to help the Municipality to improve its plans; performing a pre-prediction study of the impact of gentrification and provide a plan to organize and control real estate prices from unreasonable increases that could exacerbate current housing issues in Jeddah and surround the channels; and (5) involving landscape architects at the decision table and especially those with the proper knowledge of green infrastructure stormwater management practices (i.e., Low Impact Development LID) and ways of implementation; leveraging the new vision of the country and become one of the first municipalities to promote effective actions that implement sustainability and resiliency in these projects. For further details about design implications and scenarios read (Bogis, 2015) at (https://vtechworks.lib.vt.edu/handle/10919/73551). 


\section{References}

Morar, T., Radoslav, R., Spiridon, L.C. and Pcurar, L. (2014). Assessing pedestrian accessibility to green space using GIS. Transylvanian Review of Administrative Sciences. 10(42), 116-139.

EPA-US. Available online: https://www.epa.gov/sites/production/files/201510/documents greeninfrastructure_ collaborative2014_0.pdf(Accessed on 12/15/2017).

Bogis, A.M. (2015). The cultural-social benefits of developing green channels: Case studies and demonstration in Jeddah City, Saudi Arabia. Master Thesis, Virginia Tech, Blacksburg, Virginia, 5/7/2015

Jeddah Municipality (2014a). Open space and leisure: supply, location and distribution section. Online report. (Accessed on $1 / 6 / 2014)$.

Gehl, J. (2011). Life between buildings: using public space. Island Press: Washington, DC. p. 12, ISBN-13: 978-1-59726$827-1$.

Police-UK. Available online: https://www.police.uk/crime-prevention-advice/anti-social-behaviour/(Accessed on 10/5/ 2017).

[Al-Ekhbariah TV Channel]. (2012, Sep 11 (Desalination in Saudi Arabia) [Video File]. Retrieved from https:// www.youtube.com/watch?v=92i8-UQsI30

Jeddah Municipality (2014b). Jeddah strategic plan: Infrastructure section. Online report. (Accessed on 1/6/2014).

Isnasious, Z. (2014). (AECOM, Jeddah). Personal communication.

Burckhardt, J. (1829). Comprehending an account of those territories in Hedjaz which the Mohammedans regard as sacred. In Travels in Arabia, 2 vols.; Henry Colburn, London.

Waterfall, P. (2004). Harvesting rainwater for landscape use, $2^{\text {nd }}$ ed.; The University of Arizona: Tucson, AZ. p. 20.

Al-Hathloul, S. A. and Anis-ur-Rahmaan, S. (1985). The evolution of urban and regional planning in Saudi Arabia. Ekistics. 206-212. Rahman (eds) the imperial of urban and regional planning: Concepts and case studies from the developing world, Xlibris Corporation, 359-374

Guizani, M. (2016). Storm water harvesting in Saudi Arabia: A multipurpose water management alternative. Water Resources Management. 30(5), 1819-1833. doi:10.1007/s11269-016-1255-4

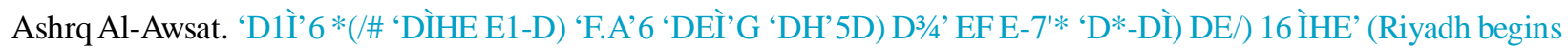
today the phase of water drop from desalination plants for 16 days). Available online on: http://archive.aawsat.com/ details.asp?article=282710\&issueno=9574\#.WiLyUkqnFPY (Accessed on 10/14/2014)

Cooke, R.U. (1982). Urban geomorphology in drylands; New York: Published on behalf of the United Nations University by Oxford University Press.

Vincent, P. (2003). Jeddah's environmental problems. Geographical Review. 93(3), 394-412. doi:10.1111/j.19310846.2003.tb00039.x

Darwish M.A., Al-Najem N.M. and Lior N. (2009). Towards sustainable sweater desalting in the gulf area. Desalination. 235, 58-87.

Cite this article as: A bdulmueen Bogis, Dean Bork and Patrick Miller (2021). Are green infrastructure strategies suitable in arid climates? a design feasibility study from Jed dah city, Saudi A rabia. International Journal of A rchitectureand Planning. 1(1), 9-18. doi: 10.51483/ IJARP.1.1.2021.9-18. 